Supporting Information for the Manuscript Entitled

\title{
Simultaneous, Segregated Storage of Two Agents in a Multicompartment Micelle
}

Timothy P. Lodge*, April Rasdal, Zhibo Li, and Marc A. Hillmyer

Department of Chemistry, University of Minnesota, 207 Pleasant Street SE, Minneapolis, MN 55455-0431; lodge@chem.umn.edu 


\section{Experiments}

Materials. Polyethylene oxide (PEO) $\left(\mathrm{M}_{\mathrm{n}}=5 \mathrm{~kg} / \mathrm{mol}\right.$, PDI $=1.09$ by SEC), pyrene (Py), naphthalene, perfluorooctanoyl acid chloride (PFOC), and oxalyl chloride were purchased from Sigma-Aldrich and used as received. Acid end-functionalized polyperfluoropropylene oxide (PFPO-COOH) was provided by Dupont. Middle hydroxyl-functionalized polyethyethylenepolyethylene oxide (EO) was synthesized by sequential anionic polymerization of butadiene and ethylene oxide, with the butadiene block fully hydrogenated prior to initiating ethylene oxide polymerization. The $\mu$-(polyethylethylene)(polyethylene oxide)(polyperfluoropropylene oxide) ( $\mu$-EOF) mikto-arm star was completed by a coupling reaction of EO and the acid chloride endfunctionalized polyperfluoropropylene oxide (PFPO-COCl). The detailed synthesis and characterization have been described. ${ }^{1}$ Methoxy-nonafluorobutane (HFE-7100) and perfluorohexane (PF-5060) were purchased from 3M.

General Methods. UV/Vis spectra of micelle solutions containing dye(s) were taken on a Spectronic Genesys-5 spectrometer using the pristine micelle solution as a reference. NMR spectra were acquired using a Varian INOVA 300 or 500 spectrometers at room temperature. PFPO was dissolved in Freon-113. The OF(5-2) diblock copolymer was dissolved in a mixture of $\mathrm{CDCl}_{3}$ and Freon-113 (ca. 50:50, v/v). All other samples were dissolved in $\mathrm{CDCl}_{3}$. Elemental analysis was performed by Atlantic Microlab (Georgia) and the experimental error was within $0.3 \%$. All the analyses were duplicated and the averaged results were used. The electrospray ionization (ESI) time-of-flight (TOF) mass spectrometry (MS) was performed on Bruker BioTOF II.

Synthesis of $\alpha$-naphthyl perfluoroheptanyl ketone (NFH). NFH was prepared by a FriedelCraft reaction of naphthalene and $\mathrm{PFOC}$ using anhydrous $\mathrm{AlCl}_{3}$ as catalyst. Under an argon 
purge naphthalene, anhydrous $\mathrm{AlCl}_{3}$, and anhydrous dichloromethane (DCM) (200 mL) were cooled down to $0{ }^{\circ} \mathrm{C}$ in an ice bath. PFOC as a limiting agent was slowly injected into the mixture. The solution was stirred at $0{ }^{\circ} \mathrm{C}$ for two hours before it was quenched by water. The product was extracted with DCM. A yellow product was obtained after removing the DCM solvent using rotary evaporation. The yield was about $90 \%$. The crude product was purified through cold crystallization in perfluorohexane. After double recrystallization, the NFH provided colorless crystals with $99 \%$ purity by NMR and gas chromatography. All the analyses were duplicated and the averaged results were used. Elemental analysis for $\mathrm{NFH}\left(\mathrm{C}_{18} \mathrm{H}_{7} \mathrm{~F}_{15} \mathrm{O}\right)$ : theory, C, 41.24\%; H, 1.35\%; F, 54.36\%; O: 3.05; found, C, 41.27\%; H, 1.39\%; F, 54.64\%; O: N/A. (The data for O was not available due to high F content). ESI-TOF-MS: Calculated for $\mathrm{C}_{18} \mathrm{H}_{7} \mathrm{~F}_{15} \mathrm{O}(\mathrm{M}+\mathrm{Na})^{+} 547.0150 \mathrm{~g} / \mathrm{mol}$, found $547.0152 \mathrm{~g} / \mathrm{mol} .{ }^{13} \mathrm{C}$ NMR for $\mathrm{C}_{18} \mathrm{H}_{7} \mathrm{~F}_{15} \mathrm{O}, \delta(\mathrm{ppm})$ : $183.1\left({ }^{2} J_{\mathrm{C}-\mathrm{F}}=26 \mathrm{~Hz}\right), 136.4,133.3,132.2,130.3,130.1,129.0,128.8,127.8,127,4,124,4,120.6$, $118.3,116,113,5111.1,108.7$, and 106.4.

Synthesis of PEO-PFPO diblock copolymer [OF(5-2)]. The carboxylic acid group in PFPO$\mathrm{COOH}$ was converted to an acid chloride group by a reaction with oxalyl chloride in methoxynonafluorobutane at $60{ }^{\circ} \mathrm{C} .{ }^{1}$ The coupling reaction between PEO and PFPO-COCl was performed in a mixture of $\alpha, \alpha, \alpha$-trifluorotoluene and methoxy-nonafluorobutane (50:50, $\mathrm{v} / \mathrm{v})$ at $60{ }^{\circ} \mathrm{C}$ for 24 hours. The product was then purified according to an established procedure. ${ }^{1}$

Dynamic Light Scattering (DLS). The samples were investigated using a home-built photometer equipped with an electrically heated silicon oil index-matching bath, a Lexel 75 $\mathrm{Ar}^{+}$laser operating at $488 \mathrm{~nm}$, a Brookhaven BI-DS photomultiplier, and a Brookhaven BI-9000 correlator. $^{2}$ The intensity correlation function, $\mathrm{g}^{(2)}(\mathrm{t})$, was recorded at room temperature, and the measurements were usually made at five angles between $50^{\circ}$ and $130^{\circ}$. When the measured and 
the calculated baselines were in good agreement (difference $<0.1 \%$ ), the correlation function was accepted. An inverse Laplace transformation was performed using the constrained regularization calculation program $\operatorname{REPES}^{3}$ to obtain the distribution of relaxation times, which can be converted into hydrodynamic radius using Stokes-Einstein equation. The probability-toreject parameter was maintained at 0.5 .

Cryogenic Transmission Electron Microscopy (cryoTEM). CryoTEM samples were prepared in a controlled environment vitrification system (CEVS), ${ }^{4}$ which was humidified to saturation of water vapor. All the samples were prepared at room temperature. Typically, a micropipette was used to load a drop of micelle solution $(5 \mu \mathrm{L})$ onto a lacey supported grid, held by tweezers. The excess solution was blotted by a piece of filter paper, resulting in the formation of thin films of $100 \sim 300 \mathrm{~nm}$ thickness in the grid holes. After about 20 seconds relaxation, the samples were quickly plunged into a reservoir of liquid ethane at melting temperature $(\sim 90 \mathrm{~K})$ cooled by liquid nitrogen. The prepared samples were stored in liquid nitrogen before they were transferred to the cryogenic sample holder (Gatan 626). The vitrified samples were examined with a JEOL 1210 TEM $(120 \mathrm{Kv})$ at $-178{ }^{\circ} \mathrm{C}$. The phase contrast was enhanced by underfocus. The images were recorded on a Gatan 724 multiscan CCD and processed with DigitalMicrographs version 3.3.1. The ramp-shaped optical density gradients in the background were digitally corrected. In the cryoTEM images shown in this paper, the $\mathrm{F}$ domains appear dark and $\mathrm{E}$ domains appear gray due to intrinsic electron density differences. The PEO corona is solvated with water and is normally invisible.

Dye Solubilization Experiment. The micelle solutions were prepared by direct dissolution of the selected copolymer in deionized water to form $1 \mathrm{wt} \%$ stock solutions, which were stirred for at least one week before loading dye molecules. The $0.5 \mathrm{wt} \%$ solutions were diluted directly 
from stock solutions. For the dye-storage experiments, excess dye was stirred with stock solution for 3 days to maximize the solubilization. The excess dye was removed through filtration using $0.45 \mu \mathrm{m}$ micro filters. The absorption spectra of Py and NFH in squalane (a chemical analog to PEE block) and in PFPO homopolymer were measured at different known concentrations within the linear regime (i.e., Beer's Law). Molar extinction coefficients at different wavelengths were obtained from linear regression analysis of absorption versus concentration calibration curves, using squalane or PFPO as solvent. The experimentally obtained calibration curves were then used to determine the Py or NFH concentrations in the aqueous micelle solutions. The solubilities of Py in $\mathrm{H}_{2} \mathrm{O}$ and in PFPO, and of $\mathrm{NFH}$ in $\mathrm{H}_{2} \mathrm{O}$, were sufficiently low that they could be neglected. The maximum concentration of Py and NFH in each micelle solution was calculated using Beer's Law: $A=\varepsilon b c$ where $\varepsilon$ is the molar extinction coefficient, $\mathrm{B}$ is the path length $(1 \mathrm{~cm})$ and $\mathrm{c}$ is the concentration in $\mathrm{mol} / \mathrm{L}$.

\section{Results}

NMR of NFH. Figure $\mathrm{S} 1$ shows the ${ }^{1} \mathrm{H},{ }^{19} \mathrm{~F}$, and ${ }^{13} \mathrm{C}$ NMR spectra of NFH after double coldrecrystallization in perfluorohexane (PFH). The proton resonances are assigned in Figure S1(a). The relative integration for each F resonance is indicated in Figure S1(b). There are 18 carbons found in Figure S1(c), where the multiple peaks for carbon atoms of perfluoheptanyl side chain were induced by the coupling of F-C. Both spectra are clean without significant impurity. Because excess naphthalene was used in the Friedel-Craft addition reaction, most of the PFOC should be consumed. When the dried product mixture was mixed with PFH, most of the desired NFH product will selectively dissolved in PFH due to the low solubility of naphthalene in PFH. A colorless crystal with high purity was obtained after double cold-recrystallization in PFH as demonstrated by NMR and GC (99\%). 

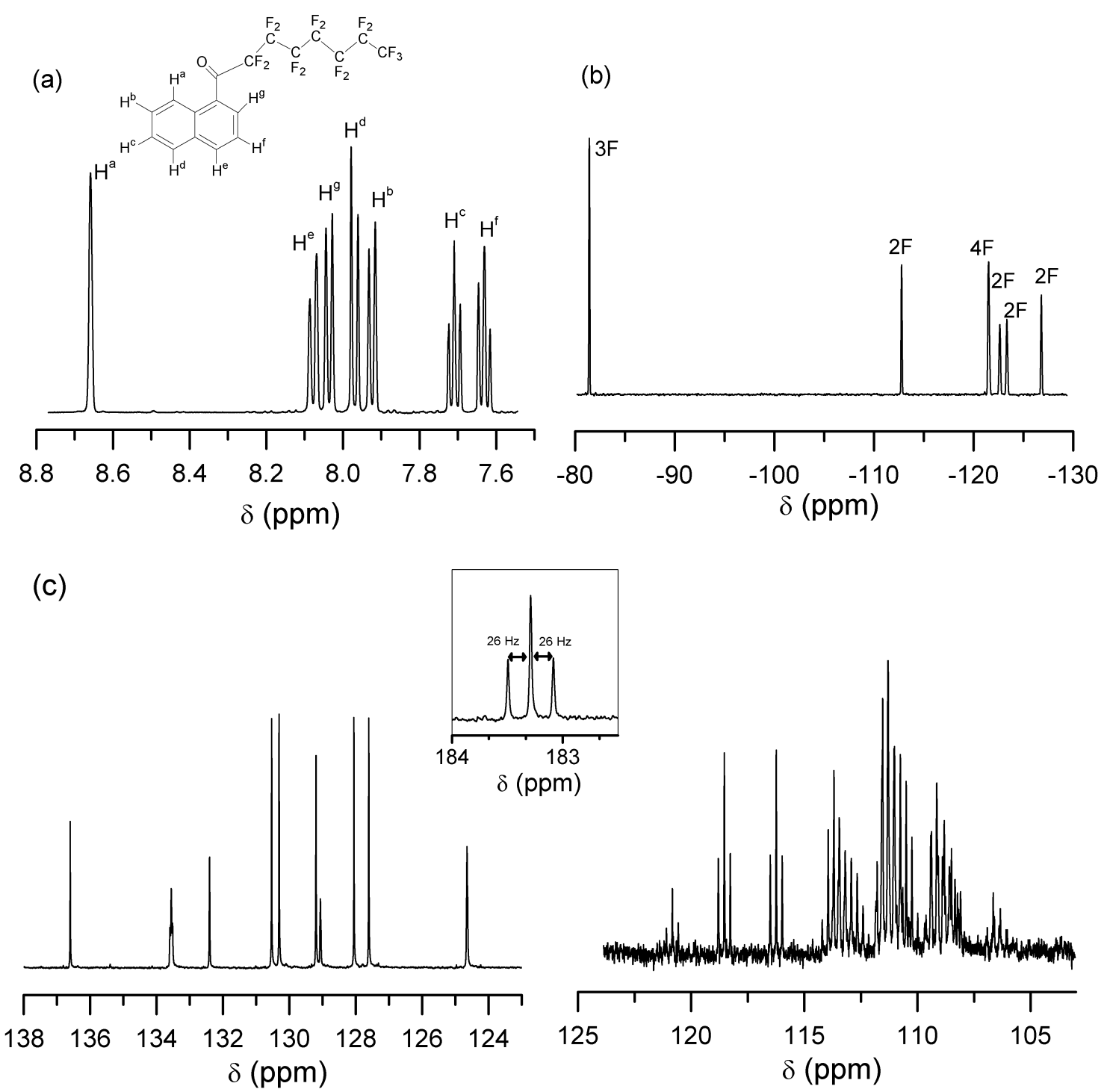

Figure S1. (a) ${ }^{1} \mathrm{H}-\mathrm{NMR}$ of NFH, (b) ${ }^{19} \mathrm{~F}-\mathrm{NMR}$ of NFH. The number represents the amount of $\mathrm{F}$ atoms for each $\mathrm{F}$ resonance. $(\mathbf{c}){ }^{13} \mathrm{C}-\mathrm{NMR}$ of $\mathrm{NFH}$. 
Synthesis of OF(5-2) Diblock Copolymer. The OF(5-2) diblock copolymer was prepared according to an established procedure. ${ }^{1}$ Analysis of the reaction products by ${ }^{1} \mathrm{H}$ and ${ }^{19} \mathrm{~F}$ NMR spectroscopy confirmed the suggested coupling reaction. Figure S2(a) shows the ${ }^{1} \mathrm{H}-\mathrm{NMR}$ characteristics of the PEO block before and after coupling. Upon reaction of the acid chloride in PFPO-COCl with the terminal hydroxyl group in PEO, the resonance of the methylene protons alpha to this hydroxyl group was shifted from $\delta=3.35 \mathrm{ppm}$ (singlet) to $\delta=4.5 \mathrm{ppm}$ (multiplet). The ${ }^{19}$ F-NMR spectra of the same OF(5-2) diblock and the PFPO-COCl precursor are shown in Figure S2(b). The characteristic resonance associated with the F adjacent to the carbonyl group of the acid chloride in PFPO-COCl shifted from $\delta=-127$ ppm to $\delta=-133$ ppm upon conversion to the ester group resulting from reaction of the hydroxyl group from PEO with PFPO-COCl. The broad peak is due to partial micelle formation of OF(5-2) in solvent mixture. Based on NMR data for the respective homopolymers, the calculated molecular parameters are listed in Table S1. The polydispersities were obtained from SEC analysis.

Table S1. Molecular Parameters of Block Copolymers

\begin{tabular}{lcccccc}
\hline \multicolumn{1}{c}{ Sample } & $\begin{array}{c}\mathrm{M}_{\mathrm{n}}(\mathrm{PEE}) \\
\mathrm{kg} / \mathrm{mol}\end{array}$ & $\begin{array}{c}\mathrm{M}_{\mathrm{n}}(\mathrm{PEO}) \\
\mathrm{kg} / \mathrm{mol}\end{array}$ & $\begin{array}{c}\mathrm{M}_{\mathrm{n}}(\mathrm{PFPO}) \\
\mathrm{kg} / \mathrm{mol}\end{array}$ & $f_{\text {PEO }}$ & $f_{\text {PFPO }}$ & PDI \\
\hline $\mathrm{EO}(2-13)$ & 1.9 & 12.6 & - & 0.84 & - & 1.1 \\
$\mathrm{OF}(5-2)$ & - & 5 & 2.5 & 0.77 & 0.23 & $-^{*}$ \\
$\mu-\mathrm{EOF}(2-13-2)$ & 1.9 & 12.6 & 2.5 & 0.76 & 0.09 & 1.1 \\
\hline
\end{tabular}

*Readily forms micelles in THF with very low cmc. 


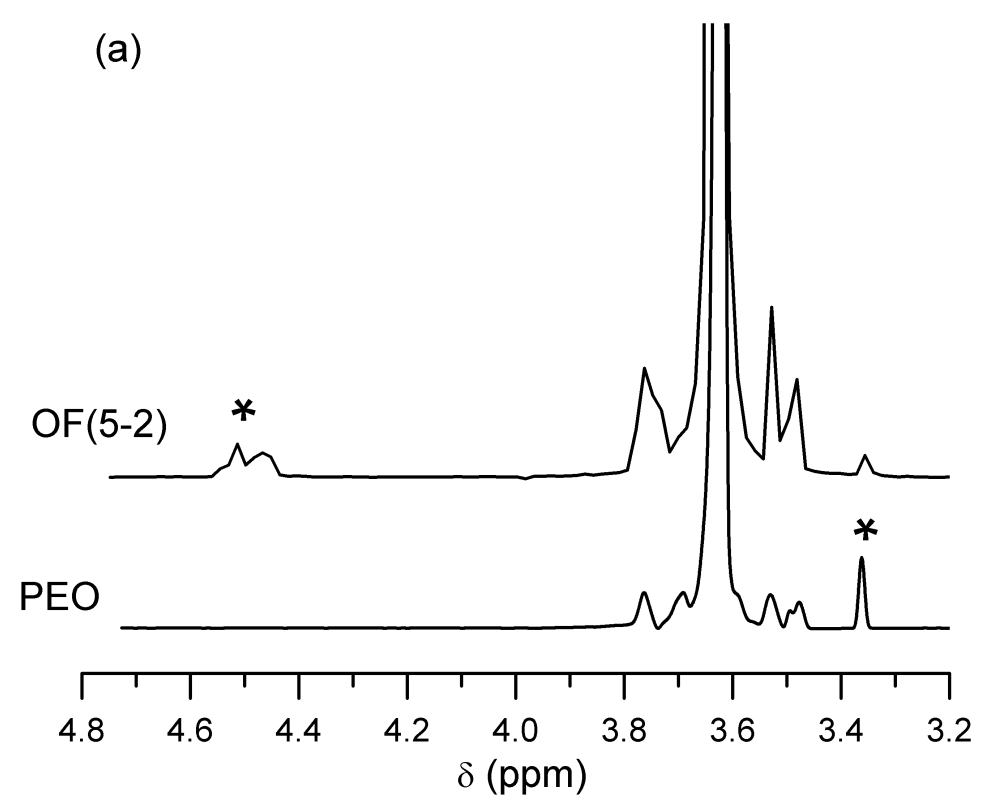

(b)

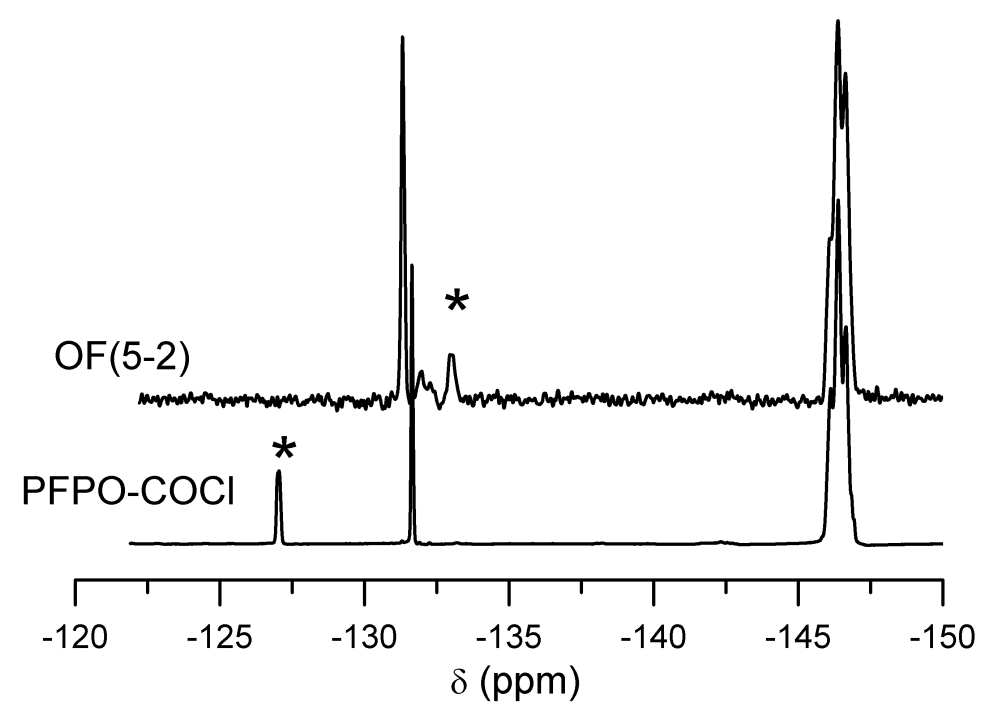

Figure S2. (a) ${ }^{1} \mathrm{H}-\mathrm{NMR}$ of PEO homopolymer and OF(5-2) diblock copolymer; (b) ${ }^{19} \mathrm{~F}-\mathrm{NMR}$ of OF(5-2) diblock copolymer and PFPO-COCl homopolymer precursor. 


\section{Micelle Formation from EO(2-13), OF(5-2), and $\mu-\operatorname{EOF}(2-13-2)$.}

The EO(2-13) diblock copolymer forms spherical micelles readily in dilute aqueous solutions. The mean hydrodynamic radius is about $30 \mathrm{~nm}$ with a narrow micelle size distribution, from cumulant analysis. ${ }^{5}$ Figure $\mathrm{S} 3$ shows a typical cryoTEM image obtained from a $1 \mathrm{wt} \% \mathrm{EO}(2-13)$ aqueous solution; the micelle cores (dark) and coronas (gray halos) are well resolved. The average radius of the micelle core is about $7.5 \pm 0.5 \mathrm{~nm}$.

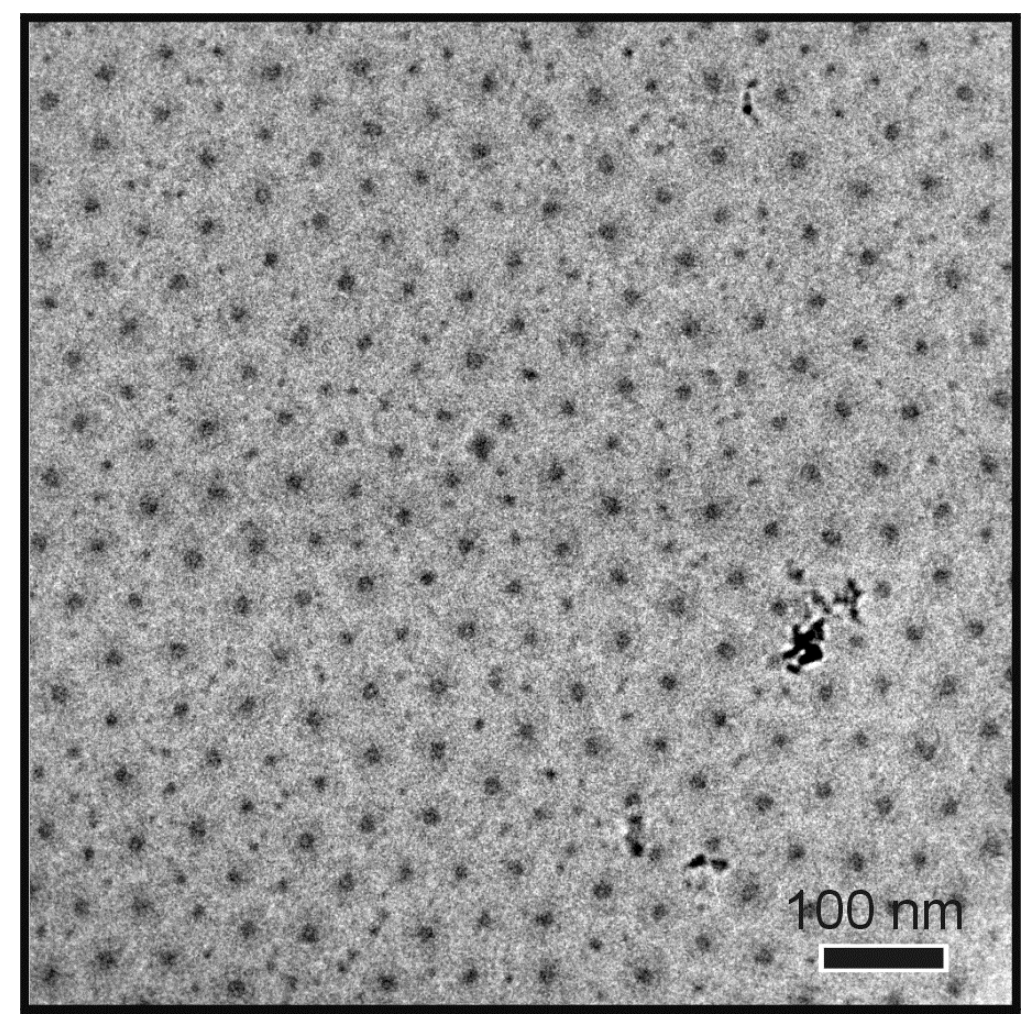

Figure S3. CryoTEM image from a $1 \mathrm{wt} \% \mathrm{EO}(2-13)$ aqueous solution. 
Due to the strong hydrophobicity of fluorocarbons, $\mathrm{OF}(5-2)$ most probably forms disk-like micelles in water following the so-called "super-strong segregation" theory. ${ }^{6,7}$ A double exponential decay model was used to fit the correlation functions, which resulted in a fast and a slow decay rate corresponding to the smaller and larger micelles, respectively; the equivalent hydrodynamic radii are about $7 \mathrm{~nm}$ and $48 \mathrm{~nm}$, respectively. Figure $\mathrm{S} 4$ (a) displays the double exponential fit results as the linear regression of decay rate versus $\mathrm{q}^{2}$. Figure $\mathrm{S} 4(\mathrm{~b})$ is the apparent micelle size distribution by REPES, ${ }^{3}$ where two types of species centered at $12 \mathrm{~nm}$ and $50 \mathrm{~nm}$ correspond to the small and large micelles.

CryoTEM was also performed on the OF(5-2) solution. Figure S5 displays a set of cryoTEM images, where the dark regime is fluorocarbon with high electron density and the PEO corona is invisible here. Apparently, the micelles formed from $\mathrm{OF}(5-2)$ have a relatively broad distribution with core radii ranging from $14 \mathrm{~nm}$ to $34 \mathrm{~nm}$. Because of the shearing from solution blotting and planar geometry confinement, the disk-like micelles tend to orient preferentially parallel to the TEM grid surface, which accounts for the absence of a side-view of a disk micelle. Considering the molecular weight of the core-forming F block, with a contour length of about $5 \mathrm{~nm}$, and an rms end-to-end distance of $6.3 \mathrm{~nm}$ for the PEO block, the formed micelles cannot be described only as spheres. From the cryoTEM images, they are clearly not worm-like micelles or vesicles. In Figure S5(d) the arrow indicates a possible, side view of a disk micelle. The detailed characterization of the micelle morphology and micellization behavior of OF diblock copolymers will be discussed elsewhere. ${ }^{8}$ However, for the purposes of this paper, it is only necessary that the OF diblocks form well-defined micelles, which is the case; the detailed geometry is not important. 

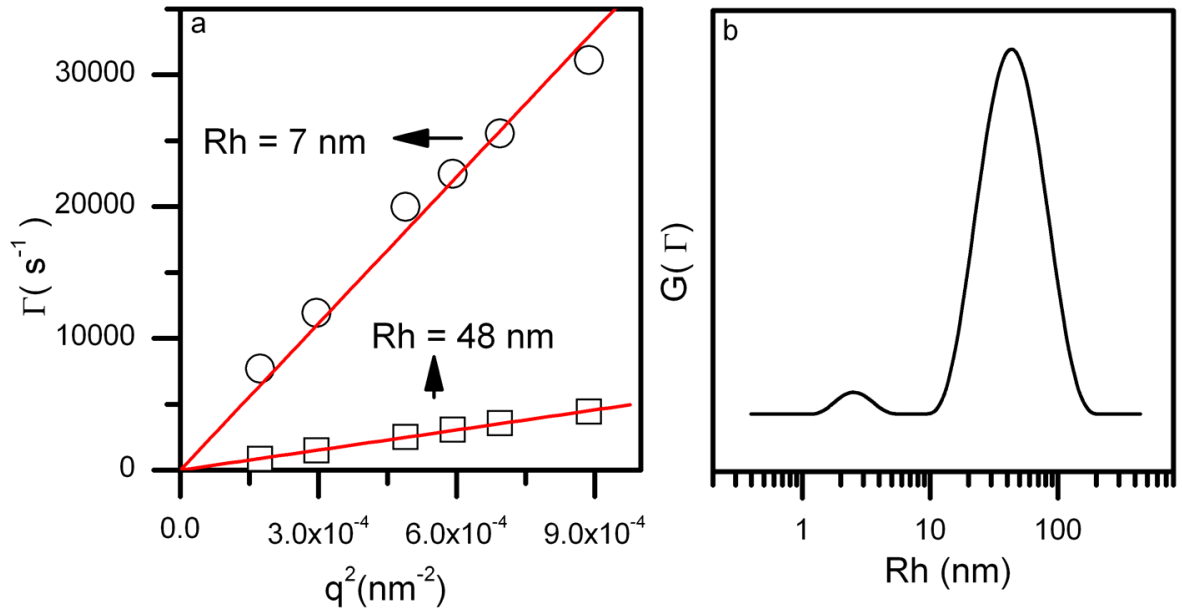

Figure S4. (a) Angle dependence of decay rates $(\Gamma)$ and $(\mathbf{b})$ apparent micelle size distribution of an $\mathrm{OF}(5-2) 1 \mathrm{wt} \%$ aqueous solution.

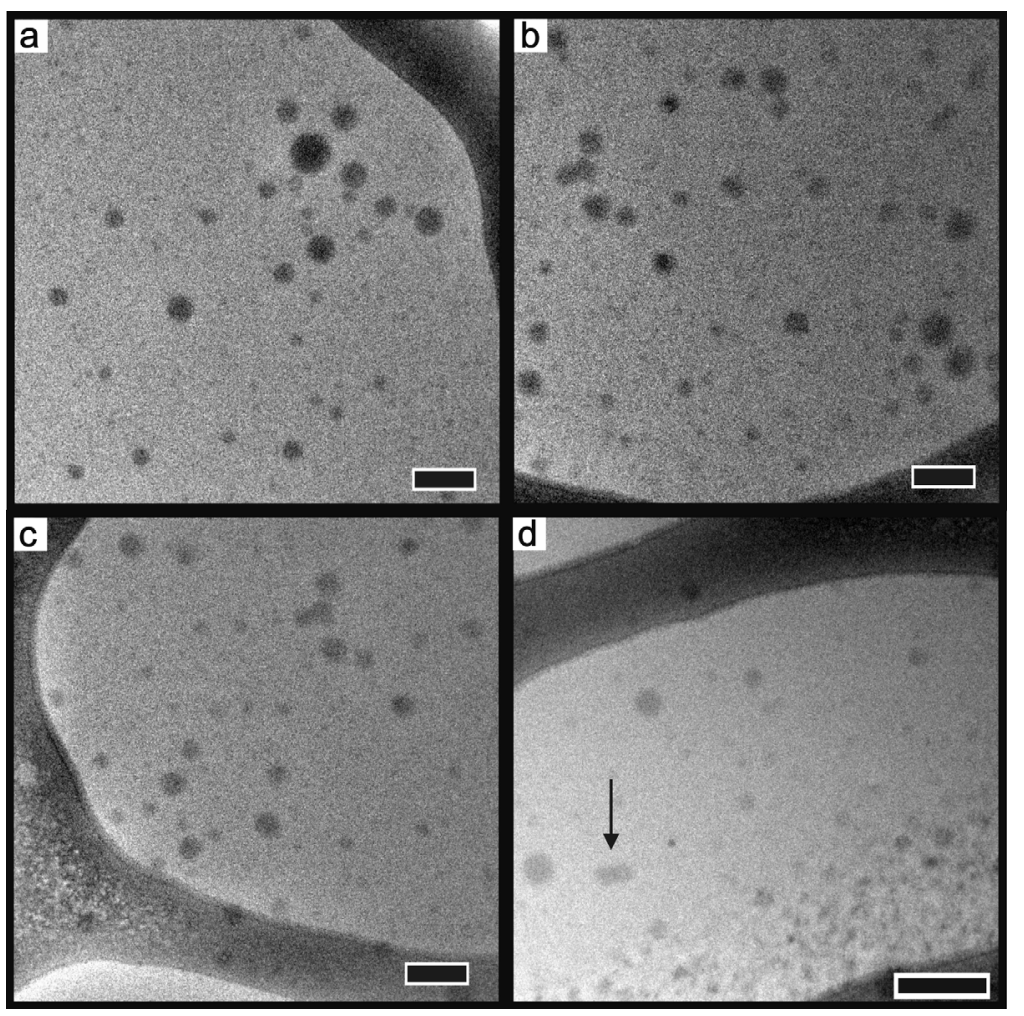

Figure S5. CryoTEM images from a $1 \mathrm{wt} \% \mathrm{OF}(5-2)$ aqueous solution. Scale bar is $100 \mathrm{~nm}$. 
As discussed previously, $\mu-\mathrm{EOF}(2-13-2)$ forms multicompartment micelles with segregated micellar cores composed of distinct, nanoscopic PFPO and PEE domains. In general, $\mu$-EOF(213-2) forms predominantly discrete micelles, with a few segmented worm-like micelles with limited length. Figure S6 displays two typical cryoTEM images as an illustration. The detailed chain-packing motif has also been described. ${ }^{9}$

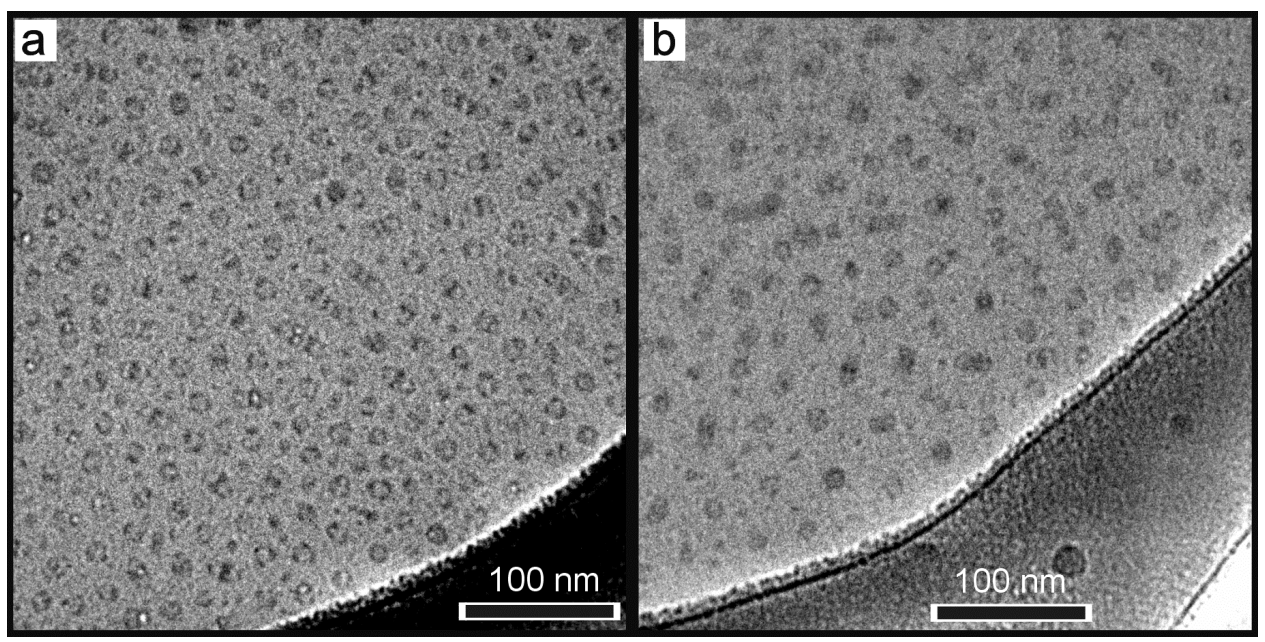

Figure S6. CryoTEM images from a $1 \mathrm{wt} \% \mu-\mathrm{EOF}(2-13-2)$ aqueous solution. 
Extinction Coefficients of Py and NFH. The molar extinction coefficients of Py and NFH were experimentally determined in squalane and PFPO homopolymer, respectively, at different wavelengths. Figure S7 summarizes the concentration dependence of the absorption spectra. The calibrations were made at 335 and $298 \mathrm{~nm}$ for further quantitative analysis. The obtained molar extinction coefficients are listed in Table S2. The extinction coefficients of Py and NFH in PEE domains were approximated by their experimentally determined extinction coefficients of Py and $\mathrm{NFH}$ in squalane, which is a chemical analogue of PEE block.

Table S2. Molar extinction coefficients of Py and NFH.

\begin{tabular}{cccc}
\hline$\lambda(\mathrm{nm})$ & $\begin{array}{c}\varepsilon_{\mathrm{Py}-\mathrm{Squ}} \\
\text { Py in squalane } \\
\left(\mathrm{L} \cdot \mathrm{mol}^{-1} \cdot \mathrm{cm}^{-1}\right)\end{array}$ & $\begin{array}{c}\varepsilon_{\mathrm{NFH}-\mathrm{Squ}} \\
\mathrm{NFH} \mathrm{in} \mathrm{squalane} \\
\left(\mathrm{L} \cdot \mathrm{mol}^{-1} \cdot \mathrm{cm}^{-1}\right)\end{array}$ & $\begin{array}{c}\varepsilon_{\mathrm{NFH}-\mathrm{PFPO}} \\
\left(\mathrm{LF} \cdot \mathrm{mol}^{-1} \cdot \mathrm{cm}^{-1}\right)\end{array}$ \\
\hline 298 & 7,500 & 20,000 & 9,700 \\
335 & 34,600 & 2,700 & 2,200 \\
\hline
\end{tabular}

Py and NFH are readily soluble in squalane and PFPO, respectively. NFH has some solubility in squalane, whereas Py has negligible solubility in PFPO homopolymer. Figure S8 shows the absorption spectrum of Py saturated in PFPO. Using a molar extinction coefficient of Py in a fluorinated solvent (methoxy-nonafluorobutane) determined to be $44,900 \mathrm{~L} \cdot \mathrm{mol}^{-1} \cdot \mathrm{cm}^{-1}$ at 328 $\mathrm{nm},{ }^{10}$ the solubility can be estimated to be $8 \times 10^{-8} \mathrm{~mol} / \mathrm{L}$, comparable to the solubility of Py in water $\left(\sim 1 \times 10^{-7} \mathrm{M}\right)$. Therefore, absorption of Py in the PFPO domain can be neglected. 

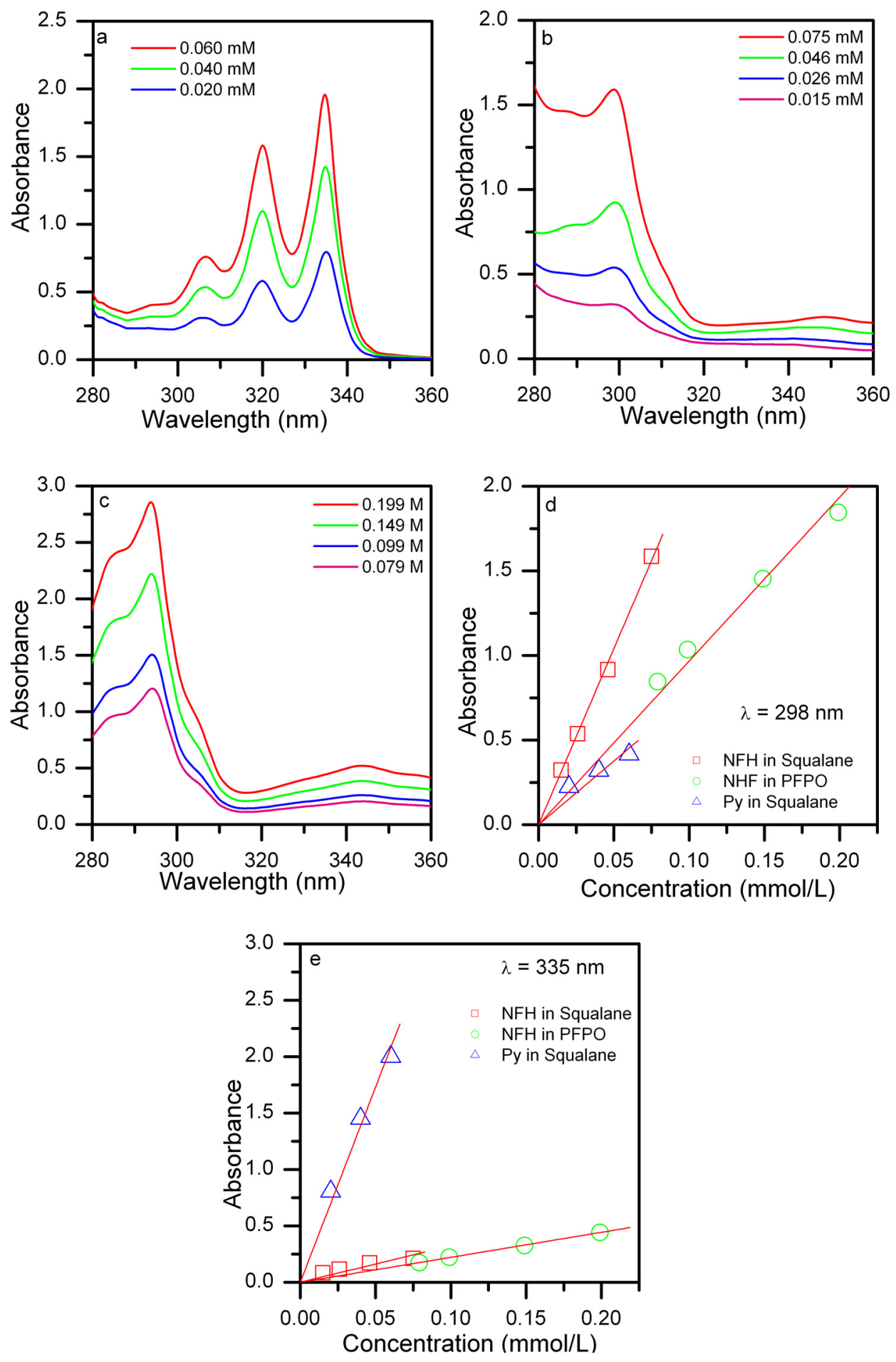

Figure S7. The absorption spectra of (a) pyrene in squalane; (b) NFH in squalane; (c) NFH in PFPO; and corresponding calibration curves at wavelength of (d) $298 \mathrm{~nm}$; (e) $335 \mathrm{~nm}$. 


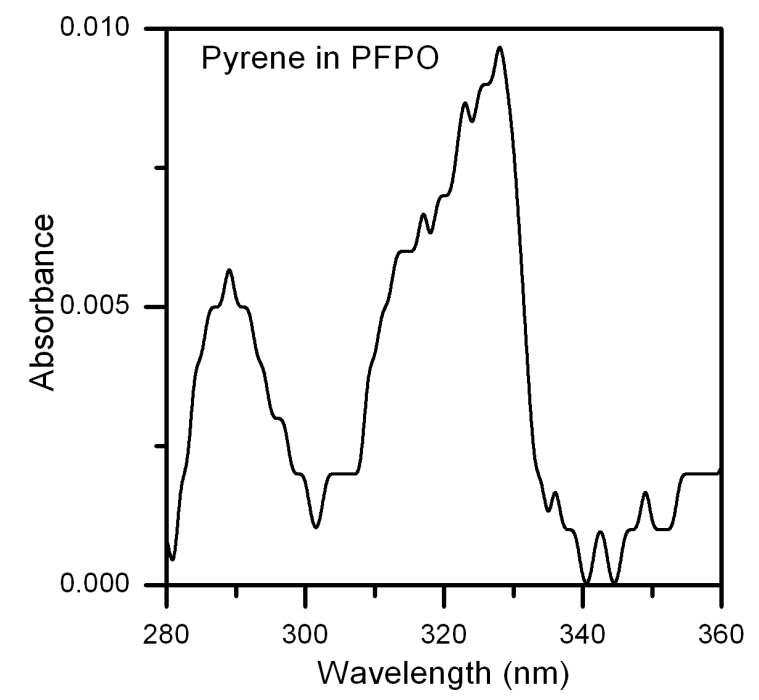

Figure S8. Absorption spectrum of saturated pyrene in PFPO homopolymer.

Absorption of Py or NFH in Micelle Solutions. In order to estimate the absorption capacity of each chromophore in $\mathrm{E}$ and $\mathrm{F}$ domains, Py and NFH were separately exposed to $0.5 \mathrm{wt} \%$ aqueous solutions of $\mathrm{EO}(2-13)$ and $\mathrm{OF}(5-2)$. For this simple "one dye in one domain" case, the concentration of absorbed dye molecules was calculated using Beer's law, $A=\varepsilon b c$. The experimental data at wavelengths of 335 and $298 \mathrm{~nm}$ were used to determine the concentration of Py in $\mathrm{EO}(2-13)$ and $\mathrm{NFH}$ in $\mathrm{EO}(2-13)$ or $\mathrm{OF}(5-2)$, respectively. The calculated results are summarized in Table S3. The storage capacity of Py in EO(2-13) was 0.16 Py molecules per PEE block, in contrast with $0.035 \mathrm{NFH}$ molecules per PEE block. Taking $7.5 \mathrm{~nm}$ as the radius of the micelle core from cryoTEM (Figure S3), the aggregation number is ca. 500 based on the known molecular weight $(2 \mathrm{kDa})$ and density of the PEE block $(0.866 \mathrm{~g} / \mathrm{mL}) .{ }^{11}$ This result indicates that each $\mathrm{EO}(2-13)$ spherical micelle can store about 80 Py molecules, but fewer than $18 \mathrm{NFH}$ molecules. OF(5-2) micelles can solubilize $0.20 \mathrm{NFH}$ molecules per polymer chain, but there was no significant uptake of Py in $\mathrm{OF}(5-2)$. 
When either Py or NFH was exposed separately to $\mu$-EOF(2-13-2) micelles, both compartments in the segregated micelle core could potentially absorb small molecules. For the case of Py in $\mu-E O F(2-13-2)$, since the solubility of Py in PFPO domains is too low to be quantified (Figure S8) by absorption spectrophotometry, we assume that the Py was absorbed solely in the PEE domain of $\mu-E O F(2-13-2)$ micelles. Using data at $335 \mathrm{~nm}$, the $\mu$-EOF(2-13-2) can take up 0.16 Py molecule per PEE chain, which is identical within experimental error with the storage capacity determined from Py in the $\mathrm{EO}(2-13)$ diblock micelle solution. For the case of NFH in $\mu$-EOF(2-13-2), the situation is more complicated because NFH has some solubility in both $\mathrm{E}$ and $\mathrm{F}$ domains. We applied two methods to estimate the total concentration of NFH in $\mu$ EOF(2-13-2). The first is to apply Beer's law simultaneously at $298 \mathrm{~nm}$ and $335 \mathrm{~nm}$ :

$$
\begin{aligned}
& A^{298}=\varepsilon_{N F H-P F P O}^{298} * c_{1} * b+\varepsilon_{N F H-S q u}^{298} * c_{2} * b \\
& A^{335}=\varepsilon_{N F H-P F P O}^{335} * c_{1} * b+\varepsilon_{N F H-S q u}^{335} * c_{2} * b \\
& c_{0}=c_{1}+c_{2}
\end{aligned}
$$

Here $c_{1}$ and $c_{2}$ are the concentrations of NFH in PFPO and PEE domains, respectively; $c_{0}$ is the total concentration of NFH in $\mu-\mathrm{EOF}(2-13-2)$ micelle solution; and $\mathrm{b}$ is the pathlength of the cell, fixed at $1 \mathrm{~cm}$. The obtained results are:

$c_{1}=5.29 \times 10^{-5} \mathrm{~mol} / \mathrm{L}$ or $0.18 \mathrm{~mol} \mathrm{NFH} / \mathrm{mol} \mathrm{PFPO}$

$c_{2}=1.02 \times 10^{-5} \mathrm{~mol} / \mathrm{L}$ or $0.035 \mathrm{~mol} \mathrm{NFH} / \mathrm{mol} \mathrm{PEE}$

$c_{0}=6.31 \times 10^{-5} \mathrm{~mol} / \mathrm{L}$ or $0.22 \mathrm{~mol} \mathrm{NFH} / \mathrm{mol} \mu-\mathrm{EOF}(2-13-2)$

The obtained storage capacity of NFH in E and F domains thus matches very well with the results obtained from $\mathrm{NFH}$ in separate $\mathrm{EO}(2-13)$ and $\mathrm{OF}(5-2)$ diblock micelle solutions. 
The other approach is to assume a partition coefficient (P) of NFH between E and F domains to be the same as that determined from its absorption in $\mathrm{EO}(2-13)$ and $\mathrm{OF}(5-2)$ diblock micelle solutions. We then can combine Eq. S1 and Eq. S2 into:

$$
A^{298}=\varepsilon_{N F H-P F P O}^{298} * c_{1} * b+\varepsilon_{N F H-S q u}^{298} * P^{*} c_{1} * b
$$

We have $P=c_{1} / c_{2}=0.16 / 0.035$. The obtained results are:

$c_{1}=5.56 \times 10^{-5} \mathrm{~mol} / \mathrm{L}$ or $0.19 \mathrm{NFH} / \mathrm{mol} \mathrm{PFPO}$

$c_{2}=8.85 \times 10^{-6} \mathrm{~mol} / \mathrm{L}$ or $0.03 \mathrm{NFH} / \mathrm{mol} \mathrm{PEE}$

$c_{0}=6.45 \times 10^{-5} \mathrm{~mol} / \mathrm{L}$ or $0.22 \mathrm{~mol} \mathrm{NFH} / \mathrm{mol} \mu-\mathrm{EOF}(2-13-2)$

The two sets of consistent results indicated that, without competition from other chromophores, the storage capacity of NFH in E or F domains is not coupled with the micelle morphology.

Competitive Solubilization of Py and NFH in Diblock Micelle Solutions. We exposed Py and NFH simultaneously to an $0.5 \mathrm{wt} \%$ aqueous solution of either $\mathrm{EO}(2-13)$ or $\mathrm{OF}(5-2)$. For the EO case, we can write:

$$
\begin{aligned}
& A^{298}=\varepsilon_{N F H-S q u}^{298} * c_{1} * b+\varepsilon_{P y-S q u}^{298} * c_{2} * b \\
& A^{335}=\varepsilon_{N F H-S q u}^{335} * c_{1} * b+\varepsilon_{P y-S q u}^{335} * c_{2} * b
\end{aligned}
$$

Here $c_{1}$ and $c_{2}$ are the concentrations of NFH and Py in E domain, respectively. Interestingly, the results gave $c_{1} \approx 0$. As $\varepsilon_{P y-S q u}^{335} \gg \varepsilon_{N F H-S q u}^{335}$ and $A^{335}>>A^{298}$, Eq. S6 can be simplified

$$
A^{335}=\varepsilon_{P y-S q u}^{335} * c_{2} * b
$$


We then obtained $c_{2}$ to be $6.43 \times 10^{-5} \mathrm{~mol} / \mathrm{L}$ or $0.18 \mathrm{~mol}$ Py per mol PEE chain. This value is quite close to the maximum storage of Py alone in $\mathrm{EO}(2-13)$ micelle solution as determined in the last section. Substitution into Eq S5 confirmed no significant amount of NFH in the E domains, in contrast to the case where NFH was exposed to EO(2-13) in the absence of Py. This conclusion is corroborated by the absorption spectra shown in Figure 9. Within the experimental uncertainty, the absorption spectra of Py in $\mathrm{EO}(2-13)$ is same as that of Py and NFH in EO(213). In particular there is no strong absorption around $298 \mathrm{~nm}$, which would be characteristic of NFH. In contrast, the absorption of NFH at $298 \mathrm{~nm}$ for Py and NFH in $\mu$-EOF(2-13-2) solution is about an order of magnitude higher than that of Py and NFH in $\mathrm{EO}(2-13)$ solution. The reason is that $\mu$-EOF(2-13-2) has both E and F domains to host Py and NFH, respectively. We therefore conclude that the E domains preferentially absorb only Py molecules from the mixture of Py and NFH.

For the case of $\mathrm{Py}$ and $\mathrm{NFH}$ in $\mathrm{OF}(5-2)$ solution, there is no reason to suspect that any solubility of Py in the F domain The calculation of NFH concentration is straightforward:

$$
A^{298}=\varepsilon_{N F H-P F P O}^{298} * c_{N F H} * b
$$

Using the data at $298 \mathrm{~nm}$, the concentration of $\mathrm{NFH}$ in $\mathrm{OF}(5-2)$ was determined to be $1.49 \times 10^{-4}$ $\mathrm{mol} / \mathrm{L}$ or $0.22 \mathrm{NFH}$ per PFPO chain. 




Figure S9. Absorption spectra of Py in EO(2-13) (red curve); Py and NFH in EO(2-13) (blue curve); Py and NFH in $\mu$-EOF(2-13-2) (green curve).

Simultaneous Solubilization of Pyrene and NFH in $\mu$-EOF(2-13-2) Micelle Solution. When the Py and NFH were exposed to an $0.5 \mathrm{wt} \%$ aqueous solution of $\mu-\mathrm{EOF}(2-13-2)$ simultaneously, strong absorption from both Py and NFH were observed as the spectrum shown in Figure S9 (solid green). A complete distribution of dye molecules includes Py or NFH in either E or F domains. However, we neglect any solubility of Py in F domains, but retain the possibility that some NFH goes into the E domains. Using three equations at the wavelengths of 298,320 and $335 \mathrm{~nm}$ to obtain the three concentrations. 


$$
\begin{aligned}
& A^{298}=\varepsilon_{N F H-P F P O}^{298} * c_{1} * b+\varepsilon_{N F H-S q u}^{298} * c_{2} * b+\varepsilon_{P y-S q u}^{298} * c_{3} * b \\
& A^{320}=\varepsilon_{N F H-P F P O}^{320} * c_{1} * b+\varepsilon_{N F H-S q u}^{320} * c_{2} * b+\varepsilon_{P y-S q u}^{320} * c_{3} * b \\
& A^{335}=\varepsilon_{N F H-P F P O}^{335} * c_{1} * b+\varepsilon_{N F H-S q u}^{335} * c_{2} * b+\varepsilon_{P y-S q u}^{335} * c_{3} * b
\end{aligned}
$$

Here $\mathrm{c}_{1}, \mathrm{c}_{2}$, and $\mathrm{c}_{3}$ correspond to the concentration of $\mathrm{NFH}$ in $\mathrm{F}$ domain, $\mathrm{NFH}$ in $\mathrm{E}$ domain, and Py in E domain, respectively. However, again the data did not give a reliable, significant value for $\mathrm{c}_{2}$. Assuming $\mathrm{c}_{2}<<\mathrm{c}_{1}$ and $\mathrm{c}_{2}<<\mathrm{c}_{3}$ we have

$$
\begin{aligned}
& A^{335}=\varepsilon_{N F H-P F P O}^{335} * c_{1} * b+\varepsilon_{P y-S q u}^{335} * c_{3} * b \\
& A^{298}=\varepsilon_{N F H-P F P O}^{298} * c_{1} * b+\varepsilon_{P y-S q u}^{298} * c_{3} * b
\end{aligned}
$$

Inserting the experimental date, we obtained the concentration of NFH in F domain $\left(c_{1}\right)$ and Py in E domain $\left(c_{3}\right)$ to be $4.19 \times 10^{-5} \mathrm{~mol} / \mathrm{L}$ or $0.14 \mathrm{~mol} \mathrm{NFH} / \mathrm{mol} \mathrm{PFPO}$, and $4.97 \times 10^{-5} \mathrm{~mol} / \mathrm{L}$ or $0.17 \mathrm{~mol} \mathrm{Py} / \mathrm{mol} \mathrm{PEE}$, respectively.

Table S3. Storage capacity of micelle solutions (moles of dye/moles of copolymer).

\begin{tabular}{ccccc}
\hline Dye & EO(2-13) & OF(5-2) & $\mu-E O F(2-13-2)^{\mathrm{a}}$ & $\mu-E O F(2-13-2)^{\mathrm{b}}$ \\
\hline Pyrene & 0.16 & - & 0.16 & 0.17 \\
NFH & 0.035 & 0.20 & 0.22 & 0.14 \\
\hline
\end{tabular}

${ }^{\mathrm{a}}$ Pyrene and NFH were exposed to an $0.5 \mathrm{wt} \% \mu-\mathrm{EOF}(2-13-2)$ independently. ${ }^{\mathrm{b}}$ Pyrene and NFH were exposed to an $0.5 \mathrm{wt} \% \mu-\mathrm{EOF}(2-13-2)$ micelle solution simultaneously. 


\section{References:}

(1) Li, Z.; Hillmyer, M. A.; Lodge, T. P. Macromolecules 2004, 37, 8933.

(2) Pan, C.; Maurer, W.; Liu, Z.; Lodge, T. P.; Stĕpánek, P.; von Meerwall, E. D.; Watanabe, H. Macromolecules 1995, 28, 1643.

(3) Jakes, J. Coll. Czech. Chem. Commun. 1995, 60, 1781.

(4) Bellare, J. R.; Davis, H. T.; Scriven, L. E.; Talmon, Y. J. Electron Microsc. 1988, $10,87$.

(5) Koppel, D. E. J. Chem. Phys. 1972, 57, 4814.

(6) Lodge, T. P.; Hillmyer, M. A.; Zhou, Z.; Talmon, Y. Macromolecules 2004, 37, 6680.

(7) Semenov, A. N.; Nyrkova, I. A.; Khokhlov, A. R. Macromolecules 1995, 28, 7491.

(8) Hillmyer, M. A.; Lodge, T. P. Unpublished Results.

(9) Li, Z.; Kesselman, E.; Talmon, Y.; Hillmyer, M. A.; Lodge, T. P. Science 2004, 306, 98.

(10) Mackay, D.; Shiu, W. Y. J. Chem. Eng. Data 1977, 22, 399.

(11) Fetters, L. J.; Lohse, D. J.; Richter, D.; Witten, T. A.; Zirkel, A. Macromolecules 1994, $27,4639$. 